Пробл. особо опасных инф. 2018; 1:12-15. DOI: 10.21055/0370-1069-2018-1-12-15

УДК 616.98:578.833.29(470)

\title{
А.С.Волынкина ${ }^{1}$, Е.С.Котенев ${ }^{1}$, Я.В.Лисицкая ${ }^{1}$, О.В.Малецкая ${ }^{1}$, Н.Д.Пакскина ${ }^{2}$, Л.И.Шапошникова ${ }^{1}$, Е.В.Яцменко 2 , А.Н.Куличенко ${ }^{1}$
}

\section{АНАЛИЗ ЗАБОЛЕВАЕМОСТИ КРЫМСКОЙ ГЕМОРРАГИЧЕСКОЙ ЛИХОРАДКОЙ В РОССИЙСКОЙ ФЕДЕРАЦИИ В 2017 г. И ПРОГНОЗ НА 2018 г.}

${ }^{1}$ ФКУЗ «Ставропольский научно-исследовательский противочумный институт», Ставрополь, Российская Федерация; ${ }^{2}$ Федеральная служба по надзору в сфере защиты прав потребителей и благополучия человека, Москва, Российская Федерация

В работе представлен анализ заболеваемости Крымской геморрагической лихорадкой (КГЛ) в Российской Федерации в 2017 г., обобщены результаты эпизоотологического обследования территории природного очага КГЛ на юге европейской части России, приведены результаты генетического типирования изолятов вируса ККГЛ. В 2017 г. в Российской Федерации зарегистрировано 78 больных КГЛ. Снижение заболеваемости отмечено в Волгоградской, Ростовской, Астраханской областях, Ставропольском крае и Республике Калмыкия. Впервые с 1967 г. зарегистрирован случай заболевания КГЛ в Республике Крым. Уровень эпизоотологической активности природного очага КГЛ в России в 2018 г. ожидается не ниже показателей 2017 г. В случае благоприятных для иксодид погодно-климатических условий зимы 2017-2018 гг., а также при несвоевременном проведении акарицидных обработок возможно увеличение численности иксодовых клещей, что в совокупности с сохраняющимся высоким уровнем инфицированности клещей $H$. marginatum вирусом ККГЛ будет способствовать росту заболеваемости КГЛ.

Ключевые слова: Крымская геморрагическая лихорадка, эпидемиологическая ситуация, эпизоотологический мониторинг, заболеваемость, прогноз.

Корреспондирующий автор: Волынкина Анна Сергеевна, e-mail: stavnipchi@mail.ru.

\section{A.S.Volynkina ${ }^{1}$, E.S.Kotenev ${ }^{1}$, Ya.V.Lisitskaya ${ }^{1}$, O.V.Maletskaya ${ }^{1}$, N.D.Pakskina ${ }^{2}$, L.I.Shaposhnikova ${ }^{1}$, E.V.Yatsmenko ${ }^{2}$, A.N.Kulichenko ${ }^{1}$ \\ Analysis of Crimean Hemorrhagic Fever Morbidity Rates in the Russian Federation in 2017 and Prognosis for 2018}

${ }^{I}$ Stavropol Research Anti-Plague Institute, Stavropol, Russian Federation; ${ }^{2}$ Federal Service for Surveillance in the Sphere of Consumers Rights Protection and Human Welfare, Moscow, Russian Federation

This paper presents the analysis of Crimean hemorrhagic fever (CHF) morbidity rates in Russia in 2017; summarized are the results of epidemiological survey of the territory of the natural CHF focus in the south of the European part of Russia, discussed are the results of genetic typing of CCHF virus isolates. In 2017, the Russian Federation reported 78 cases of CHF. Decrease in the incidence of CHF occurred in the Volgograd Region, Stavropol Territory, Astrakhan Region, Republic of Kalmykia, and Rostov Region. For the first time since 1967, CHF case has been identified in Crimea Republic. It is expected that the level of epizootic activity of CHF natural focus in Russia in 2018 will be at least equal to 2017. In case of favorable for Ixodidae ticks weather and climate conditions of the winter 2017-2018, as well as untimely acaricidal treatments, the number of Ixodidae ticks may increase, which along with the high scale of CCHF virus infection in ticks, will contribute to the increase in CHF incidence.

Key words: Crimean hemorrhagic fever, epidemic situation, epizootiological monitoring, morbidity, prognosis.

Conflict of interest: The authors declare no conflict of interest.

Corresponding author: Anna S. Volynkina, e-mail: stavnipchi@mail.ru.

Citation: Volynkina A.S., Kotenev E.S., Lisitskaya Ya.V., Maletskaya O.V., Pakskina N.D., Shaposhnikova L.I., Yatsmenko E.V., Kulichenko A.N. Analysis of Crimean Hemorrhagic Fever Morbidity Rates in the Russian Federation in 2017 and Prognosis for 2018. Problemy Osobo Opasnykh Infektsii [Problems of Particularly Dangerous Infections]. 2018; 1:12-15. (In Russian). DOI: 10.21055/0370-1069-2018-1-12-15

Крымская геморрагическая лихорадка (КГЛ) особо опасная природно-очаговая вирусная инфекция, эндемичная для территории юга европейской части России, характеризующаяся тяжелым течением болезни с высоким уровнем летальности (3-20 \%) [1]. Природные очаги КГЛ известны на территории Африки, Азии, Юго-Восточной Европы и юга европейской части России $[1,2]$.

В 2017 г. случаи заболевания КГЛ выявлены в Иране (120, летальных 8) [6], Пакистане (69, летальных 11) [11], Омане (9, летальных 3) [10], Индии (2) [4, 5], Уганде (8, летальных 2) [15], ЮАР (2) [13, 14], Намибии (2, летальный 1) [8, 9], Мавритании (3) [7],
Сенегале (3, 2 заносных случая из Мавритании) [7, 12]. Рост заболеваемости КГЛ отмечен в Афганистане: в 2017 г. выявлено 237 случаев (41 летальный), в 2016 г. - 156 (18 летальных), до 2016 г. в стране регистрировалось от 5 до 50 больных в год $[3,16]$.

КГЛ остается одной из наиболее актуальных природно-очаговых инфекций для регионов юга России. Эпидемические проявления КГЛ в Южном и Северо-Кавказском федеральных округах (ЮФО и СКФО) в период с 1999 по 2017 год зарегистрированы в 10 из 14 субъектов: Ростовской, Волгоградской, Астраханской областях, Ставропольском крае, Республиках Дагестан, Калмыкия, Ингушетия, Крым, 


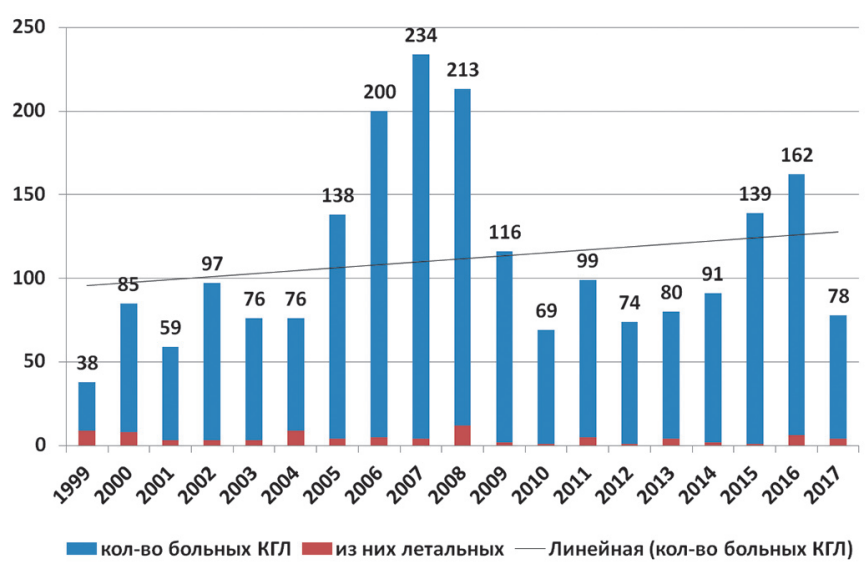

Рис. 1. Количество случаев заболевания КГЛ в Российской Федерации в 1999-2017 гг.

Карачаево-Черкесской и Кабардино-Балкарской. За 19 лет в ЮФО и СКФО выявлено 2124 больных, из них 86 (4,04\%) случаев закончились летальным исходом. Наибольшее количество случаев отмечено в Ставропольском крае - 753 (24 летальных), Ростовской области - 659 (26 летальных) и в Республике Калмыкия - 351 (10 летальных). Рост заболеваемости КГЛ наблюдался в периоды с 1999 по 2007, и с 2011 по 2016 год (рис. 1).

В 2017 г. эпидемические проявления КГЛ зарегистрированы в семи субъектах ЮФО и СКФО. Выявлено 78 случаев заболевания, что в 2,1 раза меньше, чем в 2016 г. (162 случая). Зарегистрировано четыре летальных исхода (в 2016 г. - 6). Заболевания регистрировали преимущественно в Ростовской области - 37 случаев (2 летальных), Ставропольском крае - 19, и Республике Калмыкия - 14 (1 летальный). Кроме того, в Волгоградской области выявлено 4 случая КГЛ, в Астраханской - 2 (1 летальный), в Республике Дагестан и Республике Крым по одному, при этом случай заболевания КГЛ в Республике Крым зарегистрирован впервые с 1967 г. Территориальное распределение случаев заболевания КГЛ в РФ в 2017 г. отображено на рис. 2.

Снижение уровня заболеваемости в 2017 г. отмечено практически на всей территории природного очага КГЛ: в Волгоградской области - в 3,5 раза (14 случаев в 2016 г.), в Ставропольском крае - в 3,2 раза (60 случаев в 2016 г.), в Астраханской области - в 2,5 раза (5 случаев в 2016 г.), в Республике Калмыкия в 1,8 раза (25 случаев в 2016 г.), в Ростовской области - 1,5 раза (57 случаев в 2016 г.).

Эпидемический сезон продолжался с апреля по сентябрь. Первые больные (по дате заболевания) зарегистрированы в III декаде апреля в Ставропольском крае (с. Покровское Красногвардейского района и п. Тихий Буденновского района). Заболеваемость нарастала с мая (28,2 \% от всех больных), пик пришелся на июнь (53,8 \% от всех больных), спад - на июль-август $(9,0$ и $5,1 \%)$. Последний случай заболевания отмечен в I декаде сентября в с. Троицкое Целинного района Республики Калмыкия.

Инфицирование людей происходило при реализации трансмиссивного и контактного механизмов передачи вируса Крымской-Конго геморрагической лихорадки (вирус ККГЛ). В 58,9 \% случаев инфицирование произошло из-за укуса клеща, контакт с которым отмечался в $37,2 \%$ случаев при уходе за

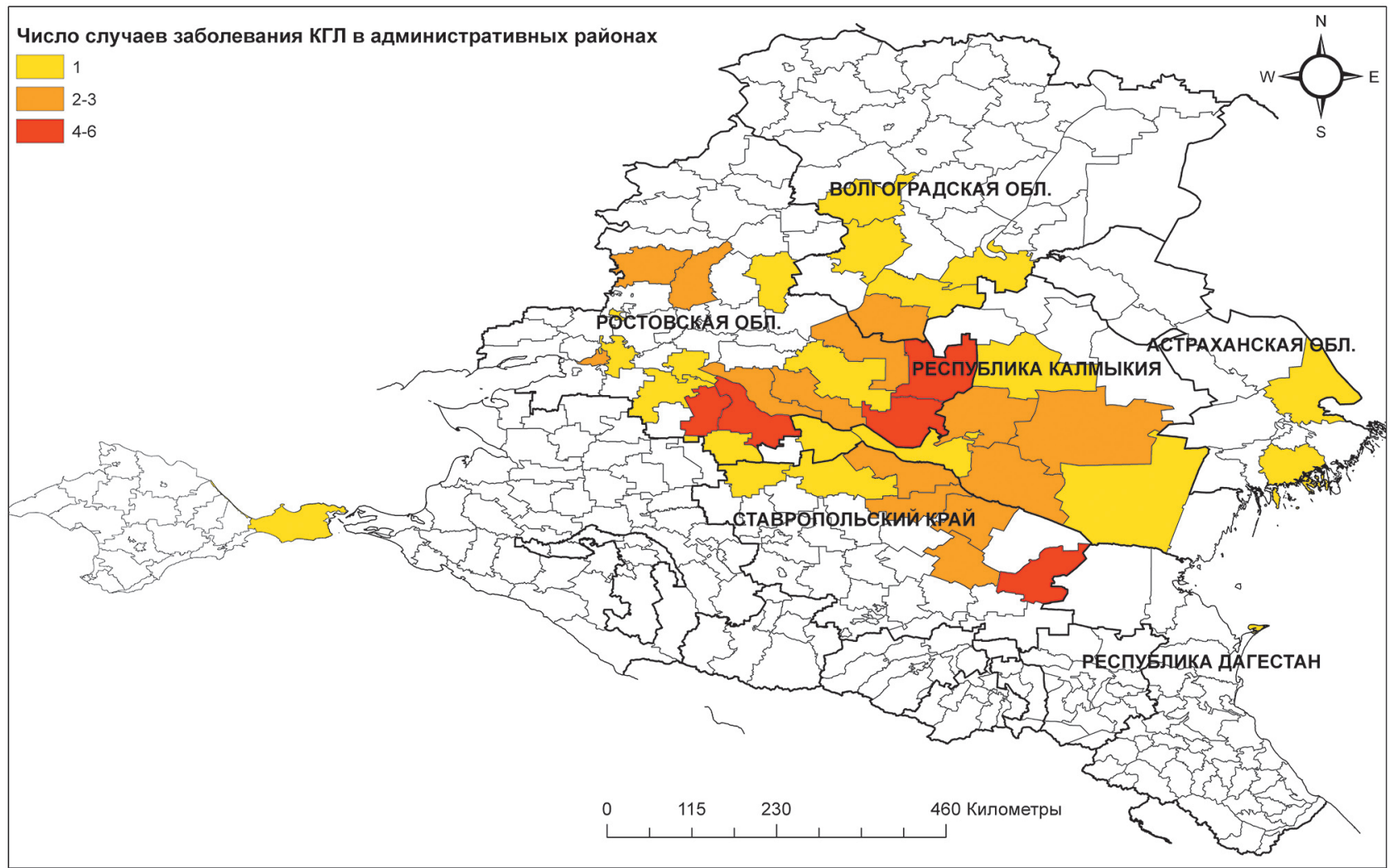

Рис. 2. Эпидемические проявления КГЛ в Российской Федерации в 2017 г. 
сельскохозяйственными животными, в 17,9 \% - при выполнении полевых работ и 5,1\% - при нахождении в природных биотопах. В 6,4 \% случаев путь заражения не установлен.

Анализ клинических проявлений КГЛ показал, что у $67,9 \%$ больных наблюдалась клиническая форма без геморрагических проявлений (в 2016 г. - у 72,8 \% больных, в 2015 - у 75,5 \%). Преобладающей была среднетяжелая форма течения болезни $(80,8 \%$ от всех случаев заболевания), в 3,8 \% случаев отмечалась легкая клиническая форма заболевания, доля случаев тяжелого течения болезни составила $15,4 \%$.

Количество лиц, обратившихся в лечебнопрофилактические организации по поводу укусов клещей, снизилось и, по состоянию на 21 сентября 2017 г., составило 33226, в том числе 12888 детей (за аналогичный период 2016 г. - 36810, в том числе 13194 детей).

Погодно-климатические условия зимы 20162017 гг. на территории юга европейской части России были относительно благоприятными для перезимовки клещей. Среднемесячные температуры зимних месяцев были на 5-7 ${ }^{\circ} \mathrm{C}$ ниже, в сравнении с периодом 2015-2016 гг.

Активизация Hyalomma marginatum, основного переносчика вируса ККГЛ, после зимней диапаузы зарегистрирована в полупустынных ландшафтах Ставропольского края (стационарные точки наблюдения) во II декаде марта 2017 г. Показатели численности иксодид (индекс встречаемости имаго H. marginatum) на крупном рогатом скоте достигали $28,2 \%$ при индексе обилия 0,4 (в 2016 г. - 92,1 \% и 5,4 соответственно), на мелком рогатом скоте индекс встречаемости - 19,4 \% при индексе обилия 0,2 (в 2016 г. $47,9 \%$ и 1,3 соответственно). Максимальный индекс обилия в одной точке сбора достигал 2,5 .

Bo II-III декадах мая 2017 г. индекс встречаемости имаго $H$. marginatum на крупном рогатом скоте достигал 84,7 \% при индекс обилия 8,3. В отдельных точках сбора индекс встречаемости достигал $100 \%$ при индексах обилия 13,4-16,4.

Уровень заклещевленности сельскохозяйственных животных в апреле-августе 2017 г. в Ставропольском крае, Ростовской, Волгоградской, Астраханской областях, Республиках Калмыкия, Дагестан и Крым в целом соответствовал прошлогодним значениям.

При эпизоотологическом обследовании территории Ставропольского края в I декаде июля 2017 г. индекс встречаемости преимагинальных фаз H. marginatum на диких птицах (грач) в стационарных точках наблюдения составил $100 \%$, индекс обилия преимагинальных фаз - 13,0 (личинок - 12,5, нимф 0,5). В I декаде августа 2017 г. индекс встречаемости преимагинальных фаз $H$. marginatum на диких птицах (грач) составил $100 \%$, индекс обилия - 125,7.

На базе лабораторий противочумных учреждений и ФБУЗ «Центр гигиены и эпидемиологии» в субъектах ЮФО, СКФО и КФО методами ИФА и ПЦР на наличие антигена и РНК вируса ККГЛ иссле- довано 2566 проб иксодовых клещей, выявлено 199 положительных (7,8 \%), в 2016 г. процент зараженности клещей составил 5,7. Доля зараженности иксодовых клещей в 2017 г. увеличилась: в Ставропольском крае - до 5,6 \% (в 2016 г. - 2,7\%), в Астраханской области - до 14,9\% (в 2016 г. - 5,6\%), в КабардиноБалкарской Республике - до 10,5 \% (в 2016 г. - 3,0 \%), в Республике Крым - до 10,8\% (в 2016 г. положительных проб не выявлено, в 2015 г. - 3,0\%), в Республике Дагестан - до 3,9 \% (в 2016 г. - 3,4 \%). В Ростовской области, напротив, выявлено вирусофорных клещей меньше - 14,9 \% (в 2016 г. - 24,8 \%). По результатам лабораторных исследований, циркуляция вируса ККГЛ в 2017 г. не выявлена на территориях Краснодарского края, Республик Ингушетия, Адыгея, Карачаево-Черкесския и Северная Осетия-Алания.

На базе Референс-центра по мониторингу за возбудителем КГЛ проведено генетическое типирование изолятов РНК вируса ККГЛ, выделенных из образца плазмы крови больного КГЛ в Крыму в 2017 г., и шести пулов клещей $H$. marginatum, собранных при проведении эпизоотологического обследования территории Республики Крым. В результате секвенирования фрагментов генома вариантов вируса ККГЛ, детектированных в образцах клинического и полевого материала, установлено, что в 2017 г. в Республике Крым одновременно циркулировали изоляты вируса ККГЛ генотипа Европа-1, относящиеся к геновариантам «Ставрополь-Ростов-Астрахань-1» (Va-Va-Va), и «Крым» (Vd-Vd-Vd).

На энзоотичных территориях ЮФО и СКФО проведены акарицидные обработки сельскохозяйственных животных, природных биотопов, в том числе пастбищ, дератизационные мероприятия, велась информационно-разъяснительная работа с населением.

Таким образом, в 2017 г. в Российской Федерации сохранялась напряженная эпидемиологическая ситуация по КГЛ, отмечено снижение уровня заболеваемости в субъектах ЮФО и СКФО по сравнению с 2016 г. Снизилось количество лиц (на 9,8 \%), обратившихся в лечебно-профилактические организации по поводу укусов клещей, но в то же время отмечено увеличение доли заболеваний с наличием геморрагического синдрома (на 4,9\%).

На стационарных точках долговременного наблюдения за природным очагом КГЛ в 2017 г. на основных прокормителях сохранялись высокие индексы обилия нимф H. marginatum - 125,7 (в 2016 г.113,7). В ранневесенний период 2018 г. показатели численности имаго $H$. marginatum останутся на уровне средних многолетних значений. Вирусофорность клещей H. marginatum в 2017 г. увеличилась и составила от 3,9 до 14,9\% (в 2016 г. - от 2,7 до 5,6 \%).

Согласно прогнозу, составленному специалистами Референс-центра по мониторингу за возбудителем КГЛ на основании результатов эпизоотологического мониторинга, уровень эпизоотологической активности природного очага КГЛ в России в 2018 г. ожидается не ниже показателей 2017 г. В случае бла- 
гоприятных для иксодид погодно-климатических условий зимы 2017-2018 гг,, а также при несвоевременном проведении акарицидных обработок природных биотопов и сельскохозяйственных животных в марте-апреле 2018 г., показатели численности иксодовых клещей могут превысить аналогичные показатели текущего года, что в совокупности с сохраняющимся достаточно высоким уровнем вирусофорности клещей $H$. marginatum будет способствовать увеличению заболеваемости людей по сравнению с 2017 г. Для стабилизации эпидемиологической ситуации по КГЛ необходимо активизировать на всей территории природного очага КГЛ в России проведение информационно-разъяснительной работы среди населения, а также ежегодно проводить в ранневесенний период акарицидные обработки скота и природных биотопов на эндемичной по КГЛ территории.

Конфликт интересов. Авторы подтверждают отсутствие конфликта финансовых/нефинансовых интересов, связанных с написанием статьи.

\section{СПИСОК ЛИТЕРАТУРЫ}

1. Куличенко А.Н., Малецкая О.В., Василенко Н.Ф., Бейер А.П., Санникова И.В., Пасечников В.Д., Ковальчук И.В., Ермаков А.В., Бутаев Т.М., Смирнова С.Е., Карань Л.С., Малеев В.В., Платонов А.Е. Крымская геморрагическая лихорадка в Евразии в XXI веке: эпидемиологические аспекты. Эпидемиол. и инф. бол. Актуальные вопр. 2012; 3:42-53.

2. Смирнова С.Е. Крымская-Конго геморрагическая лихорадка (этиология, эпидемиология, лабораторная диагностика). М.: АТиСО; 2007. 302 c.

3. Crimean-Congo hemorrhagic fever - Afganistan (03): 2017 cases, WHO [Internet]. 2017-12-23 [cited 15 Jan 2018]. Archive Number: 20171223.5519514. Available from: http://www. promedmail.org.

4. Crimean-Congo hemorrhagic fever - India: (GJ) [Internet]. 2017-07-28 [cited 15 Jan 2018]. Archive Number: 20170728.5211266. Available from: http://www.promedmail.org.

5. Crimean-Congohemorrhagic fever-India(02): (GJ) [Internet]. 2017-11-12 [cited 15 Jan 2018]. Archive Number: 20171112.5439276. Available from: http://www.promedmail.org.

6. Crimean-Congo hemorrhagic fever - Iran (05): update [Internet]. 2017-09-26 [cited 15 Jan 2018]. Archive Number: 20170926.5342228. Available from: http://www.promedmail.org.

7. Crimean-Congo hemorrhagic fever - Mauritania (02): (NN) [Internet]. 2017-11-29 [cited 15 Jan 2018]. Archive Number: 20171129.5472475. Available from: http://www.promedmail.org.

8. Crimean-Congo hemorrhagic fever - Namibia: $(\mathrm{OH})$ fatal, quarantine [Internet]. 2017-02-27 [cited 15 Jan 2018]. Archive Number: 20170227.4866654. Available from: http://www.promedmail.org.

9. Crimean-Congo hemorrhagic fever - Namibia (02): (OH) [Internet]. 2017-03-12 [cited 15 Jan 2018]. Archive Number: 20170312.4895357. Available from: http://www.promedmail.org. 10. Crimean-Congo hemorrhagic fever Oman: case numbers [Internet]. 2017-03-23 [cited 15 Jan 2018]. Archive Number: 20170323.4920700. Available from: http://www.promedmail.org.

11. Crimean-Congo hemorrhagic fever - Pakistan (17): (Balochistan) [Internet]. 2017-10-09 [cited 15 Jan 2018]. Archive Number: 20171009.5367524. Available from: http://www.promedmail.org. 12. Crimean-Congo hemorrhagic fever-Senegal:(FK) [Internet]. 2017-07-26 [cited 15 Jan 2018]. Archive Number: 20170726.5205146. Available from: http://www.promedmail.org.

13. Crimean-Congo hemorrhagic fever - South Africa: (WC) [Internet]. 2017-01-13 [cited 15 Jan 2018]. Archive Number: 20170113.4762405. Available from: http://www.promedmail.org. 14. Crimean-Congo hemorrhagic fever - South Africa (02): (NC) [Internet]. 2017-02-03 [cited 15 Jan 2018]. Archive Num- ber: 20170203.4812066. Available from: http://www.promedmail.org. 15. Crimean-Congo hemorrhagic fever - Uganda (02) [Internet] 2017-09-06 [cited 15 Jan 2018]. Archive Number: 20170906.5299656. Available from: http://www.promedmail.org.

16. Papa A., Weber F., Hewson R., Weidmann M., Köksal I., Korukluoğlu G., Mirazimi A. Meeting report: First International Conference on Crimean-Congo hemorrhagic fever. Antiviral Res. 2015; 120:57-65. DOI:10.1016/j.antiviral.2015.05.005.

\section{References}

1. Kulichenko A.N., Maletskaya O.V., Vasilenko N.F., Beyer A.P., Sannikova I.V., Pasechnikov V.D., Koval'chuk I.V., Ermakov A.V., Butaev T.M., Smirnova S.E., Karan' L.S., Maleev V.V., Platonov A.E. [Crimean hemorrhagic fever in Eurasia in XXI century: epidemiological aspects]. Epidemiol. Infek. Bol. Aktual. Vopr. 2012; 3: 42-53.

2. Smirnova S.E. [Crimean-Congo Hemorrhagic Fever (Etiology, Epidemiology, Laboratory Diagnostics)]. M.; 2007. 302 p.

3. Crimean-Congo hemorrhagic fever - Afganistan (03): 2017 cases, WHO [Internet]. 2017-12-23 [cited 15 Jan 2018]. Archive Number: 20171223.5519514. Available from: http://www.promedmail.org. 4. Crimean-Congo hemorrhagic fever - India: (GJ) [Internet]. 2017 07-28 [cited 15 Jan 2018]. Archive Number: 20170728.5211266. Available from: http:///www.promedmail.org.

2017-11-12 [cited 15 Jan 2018] Arever - India (02): (GJ) [Internet]. Available from: http://www.promedmail.org.

6. Crimean-Congo hemorrhagic fever - Iran (05): update [Internet]

6. Crimean-Congo hemorrhagic fever - Iran (05): update [nternet].
2017-09-26 [cited 15 Jan 2018]. Archive Number: 20170926.5342228. Available from: http://www.promedmail.org.

7. Crimean-Congohemorrhagic fever-Mauritania(02):(NN) [Internet]. 2017-11-29 [cited 15 Jan 2018]. Archive Number: 20171129.5472475. Available from: http://www.promedmail.org.

8. Crimean-Congo hemorrhagic fever - Namibia: $(\mathrm{OH}) \mathrm{fa}-$ tal, quarantine [Internet]. 2017-02-27 [cited 15 Jan 2018]. Archive Number: 20170227.4866654. Available from: http://www.promedmail.org. 9. Crimean-Congo hemorrhagic fever - Namibia (02): (OH) [Internet]. 2017-03-12 [cited 15 Jan 2018]. Archive Number: 20170312.4895357.
Available from: http://www.promedmail.org.

10. Crimean-Congo hemorrhagic fever-Oman: case numbers [Internet] 2017-03-23 [cited 15 Jan 2018]. Archive Number: 20170323.4920700. Available from: http://www.promedmail.org.

11. Crimean-Congo hemorrhagic fever - Pakistan (17): (Balochistan) [Internet]. 2017-10-09 [cited 15 Jan 2018]. Archive Number: 20171009.5367524. Available from: http://www.promedmail.org. 12. Crimean-Congo hemorrhagic fever - Senegal: (FK) [Internet]. 2017-07-26 [cited 15 Jan 2018]. Archive Number: 20170726.5205146. Available from: http://www.promedmail.org. 13. Crimean-Congo hemorrhagic fever-South Africa: (WC) [Internet].
2017-01-13 [cited 15 Jan 2018]. Archive Number: 20170113.4762405. Available from: http://www.promedmail.org.

(02): 14. Crimean-Congo hemorrhagic fever - South Africa Number: 20170203.4812066. Available from: http://www.promedmail.org. 15. Crimean-Congo hemorrhagic fever - Uganda (02) [Internet]. 201709-06 [cited 15 Jan 2018]. Archive Number: 20170906.5299656. Available from: http://www.promedmail.org.

16. Papa A., Weber F., Hewson R., Weidmann M., Köksal I., Korukluoğlu G., Mirazimi A. Meeting report:'First International Conference on Crimean-Congo hemorrhagic fever. Antiviral Res. 2015; 120:57-65. DOI:10.1016/j.antiviral.2015.05.005.

\section{Authors:}

Volynkina A.S., Kotenev E.S., Lisitskaya Ya.V., Maletskaya O.V., Shaposhnikova L.I., Kulichenko A.N. Stavropol Research Anti-Plague Institute. 13-15, Sovetskaya St., Stavropol, 355035, Russian Federation. E-mail: stavnipchi@mail.ru.

Pakskina N.D., Yatsmenko E.V. Federal Service for Surveillance in the Sphere of Consumers Rights Protection and Human Welfare. 18, Bld. 5 and 7, Vadkovsky Pereulok, Moscow, 127994, Russian Federation.

\section{Об авторах:}

Волынкина А.С., Котенев Е.С., Лисиикая Я.В., Малечкая О.В. Шапошникова Л.И., Куличенко А.Н. Ставропольский научно-исследовательский противочумный институт. Российская Федерация, 355035, Ставрополь, ул. Советская, 13-15. E-mail: stavnipchi@mail.ru.

Пакскина Н.Д., Яименко Е.В. Федеральная служба по надзору в сфере защиты прав потребителей и благополучия человека. Российская Федерация, 127994, Москва, Вадковский переулок, дом 18, строение 5 и 7. 